Página inicial: 387 - Página Final: 412

Tipo de artículo: Investigación.

\title{
Las técnicas de la "gestión social" de poblaciones impactadas por proyectos hidroeléctricos como instrumento de gobierno
}

\author{
"Social management" techniques of populations impacted by hydropower station \\ projects as a government tool
}

\author{
Recibido: abril de $2017 \quad$ Revisado: mayo de $2017 \quad$ Aceptado: junio de 2017
}

1 Ingeniero ambiental, especialista en economía, magister en Gobierno y PhD Planeación Urbana y Regional. Medellín Colombia. Contacto: gamgaviria@yahoo.es ORCID:

https://orcid.org/0000$\underline{0001-6142-0605}$
Por: Gustavo Muñoz Gaviria ${ }^{1}$

\section{Resumen}

El presente artículo analiza las técnicas y prácticas de la "gestión social" en la construcción de proyectos hidroeléctricos, como elementos de un dispositivo de gobierno para fijar las condiciones favorables a la expansión del sector. Este es un tipo de dispositivo compuesto por formas de visibilidad, enunciación, poder y subjetividad. La información empírica fue recopilada en 2014 mediante trabajo etnográfico con las poblaciones impactadas por el proyecto Hidroeléctrico Porce III, construido en Antioquia-Colombia en la década de 2000. Este abordaje permitió la desnaturalización de esas técnicas y prácticas, para situarlas en una lógica más amplia de expansión del capital, donde la autogestión de los afectados juega un papel central.

Palabras clave. Hidroeléctricas; gestión social; reasentamiento; gubernamentalidad.

\begin{abstract}
This article analyzes the techniques and practices of "social management" in the construction of hydroelectric projects, which is a governmental mechanism to set the favorable conditions concerning the expansion of the sector. This is a type of mechanism made up visibility, declaration, power, and subjectivity. The empirical data was collected in 2014, through ethnographic work with the populations impacted by the Porce III Hydroelectric Power Station Project, which was built in Antioquia, Colombia, in the decade of the 2000s. This approach let the denaturalization of those techniques and practices, in order for them to be located in a wider logic of capital growth, where selfmanagement of those affected plays a key role.
\end{abstract}

Key words: Hydroelectric Power Stations; Social Management; Resettlement; Governmentality. 


\section{Introducción}

El problema abordado en este trabajo es el desplazamiento de población generado por la construcción de proyectos hidroeléctricos. El caso que sirve de fuente de informaciones es la construcción de la central hidroeléctrica Porce III a cargo de Empresas Públicas de Medellín (EPM), en la década de 2010, en inmediación de los municipios de Guadalupe, Gómez Plata, Amalfi y Anorí, a $140 \mathrm{~km}$ al nordeste de Medellín, capital del departamento de Antioquia.

Cabe mencionar, de salida, que quien escribe participó como profesional ambiental en el proceso de reasentamiento de la población en el caso estudiado y que el conocimiento de ese fenómeno social suscitó la recualificación de la visión crítica de lo allí observado, recualificación de la cual hace parte este trabajo. Así, algunas de las informaciones aquí presentadas provienen de esa experiencia profesional previa del investigador.

Porce III se encuentra en operación desde 2010, con una capacidad de producción total de energía de 660 MW (3.416 GWh/año) (EPM, 2000). Según el boletín (EPM, 2011) informativo de EPM de septiembre de 2011 sobre o proyecto Porce III, 582 familias y 372 mineros fueron impactados. Se podría hablar de un mínimo de 2.700 personas si se usa el factor de 4 personas por familia que la propia empresa usó para hacer estimativos de población, cifra que es comúnmente inferior conforme a la realidad de los territorios rurales en Colombia. De este aproximado de 2.700, solamente un 18\% fue compensado por medio de proyectos económicos, el restante $82 \%$ fue indemnizado en dinero. Si bien la gran mayoría de la población fue desplazada e indemnizada sin que se tuviera mayor certeza sobre su destino, el siguiente análisis se enfoca en las técnicas de "gestión social" para el reasentamiento de ese $18 \%$ que permaneció en la zona del proyecto o en los municipios aledaños.

\section{Metodología}

El problema sociológico u objeto de la investigación del que se deriva este artículo es una marida a las prácticas y efectos de la "gestión social" (Muñoz, 2016) como un dispositivo de gobierno (Foucault, 1980; Deleuze, 1991; Dean, 2010), una forma de gobierno compuesta por elementos de visibilidad, enunciación, poder y subjetividad. Específicamente sobre el elemento poder, que como se verá más adelante, está según estos autores, primordialmente representado por la dimensión técnica de las prácticas de gobierno. Para entender la "gestión social" como forma de gobierno desde la perspectiva foucaultiana, conviene hacer precisión sobre algunos conceptos como poder, gobierno, gubernamentalidad, régimen de prácticas, dispositivo, genealogía y analítica de gobierno.

Una lectura, aunque no muy exhaustiva de la obra de Foucault, permite observar que el término poder está comúnmente precedido de sustantivos como: relación, conjunto de mecanismos, etc. Así, éste deja de ser sustantivo para ejercer una función calificativa. El autor se refiere a relaciones de poder, mecanismos de poder, dispositivos de poder, etc. Más específicamente, él afirmará que el poder no es una cosa ni está en manos de algún actor determinado. Más bien, el poder se configura en una relación: "poder significa relaciones, un encadenamiento de relaciones más o menos organizado, jerárquico y coordinado" (Foucault, 1980 p. 198). Si el poder solo es posible en el marco de una relación, entonces, para estudiar el poder es necesario estudiar las formas en que se da esa relación y las estrategias de mantenimiento de esas relaciones, más que buscar el poder o sus detentores. Se observa también que 
el hecho de que el poder sea entendido como jerarquizado, implica que exista un movimiento de arriba hacia abajo, pero que al mismo tiempo exista para este autor una capilaridad de abajo hacia arriba. Para el ejercicio del poder es necesario así un anclaje en las formas de comportamiento, cuerpos y relaciones locales de poder que no deberían ser vistas como una simple proyección de un poder central (Foucault, 1980 p. 201).

Existen para Foucault dos formas opuestas de ejercer el poder en relación con la libertad. De un lado, estaría el juego reversible de libertades, el encuentro de dos estrategias intentado imponerse la una a la otra. De otro lado estaría la dominación como estado de fijación permanente de las jerarquías en donde no es posible pensar el cambio de las estructuras. Sin embargo, existiría entre esas dos, una zona que o es ni pura coerción ni puro consentimiento, se trata del gobierno, como forma de ejercicio del poder que se hace operable a través de las libertades de aquellos sobre quienes es ejercido (Dean, 2010). La tendencia que llevó a que esta forma de gobierno se impusiera sobre la soberanía y la disciplina mediante el desarrollo de una serie de dispositivos específicos de gobierno y de un conjunto de saberes, sería para Foucault lo que él denomina gubernamentalidad. Este concepto sería también entendido por él, como:

(...) el conjunto de instituciones, procedimientos, análisis y reflexiones, cálculos y tácticas que permiten ejercer esta forma bastante específica de poder [el gobierno], que tiene por objetivo la población, por forma de saber principal la economía política y por instrumentos esenciales los dispositivos de seguridad... [y el]... 'Resultado del proceso a través del cual el Estado de justicia de la Edad Media, que se tornó Estado administrativo en los siglos XV y XVI, fue poco a poco gubernamentalizado' (Foucault, 1978, p. 292)

El poder como forma de gobierno es ejercido en una suerte de medio, que Dean (2010, p. 28) entiende como el conjunto de prácticas organizadas, a través de las cuales somos gobernados y nos gobernamos a nosotros mismos, en el cual se articulan prácticas como la producción de verdad y conocimiento, que comprende múltiples formas de racionalidad práctica, técnica y de cálculo; y que están sujetas a programas para su aplicación y reforma. Este conjunto de prácticas es lo que se conoce como régimen de prácticas o régimen de gobierno y concebidos como "los arreglos históricamente constituidos a través de los cuales hacemos cosas como curar, cuidar, aliviar la pobreza, castigar, educar, entrenar y aconsejar" (Foucault, 1991 en Dean, 2010, p. 40). Analizar estos regímenes serían “... analizar programas de conducta que tienen tanto efectos prescriptivos sobre lo que debería hacerse (efectos de jurisdicción), como efectos de codificación sobre lo que debe ser conocido (efectos de 'verdad')" (Foucault, 1991, p. 75).

En consonancia con el concepto de régimen de prácticas, el concepto de dispositivo se torna fundamental en la teorización de Foucault como el concepto filosófico que describe la forma más general de interacción social para el ejercicio del poder más allá de las formas discursivas. Los dispositivos serían básicamente "estrategias de relaciones de fuerzas que sustentan y están sustentadas por tipos de conocimiento" (Foucault, 1980, p. 196), incluyendo elementos discursivos y no discursivos. Así, aquello que aparecía en los primeros estudios de Foucault como espisteme sería un caso particular de un dispositivo, de tipo discursivo. En el mismo texto de entrevistas concedidas por Foucault entre 1972 y 1977, el filósofo es interpelado sobre el concepto de dispositivo y sobre su función metodológica dentro de su trabajo. Allí el dispositivo es descrito como: 
Un arreglo completamente heterogéneo compuesto por discursos, instituciones, formas arquitectónicas, decisiones regulatorias, leyes, medidas administrativas, enunciados científicos, proposiciones filosóficas, morales y filantrópicas - en resumen, lo dicho y lo no dicho. Tales son los elementos del dispositivo. El dispositivo en sí mismo es un sistema de relaciones que puede ser establecido entre estos elementos. (Foucault, 1980, p. 194, resaltado nuestro)

Para Deleuze (1991), el dispositivo sería la forma en que se presenta la filosofía de Foucault. Deleuze lo entiende como un tipo de madeja o conjunto multilineal, cuyas líneas no determinan sistemas homogéneos (objeto, sujeto, lenguaje), sino procesos siempre en desequilibrio, que se aproximan o separan unos de otros. Estas líneas estarían en constante bifurcación contornando las tres grandes instancias distinguidas por Foucault: saber, poder y subjetividad. En su lectura, Deleuze (1991) identifica cuatro líneas que compondrían un dispositivo: líneas de visibilidad, líneas de enunciación, líneas de poder y líneas de subjetivación. La primera se refiere a la luz que el dispositivo proyecta para hacer aparecer o desaparecer los objetos del dispositivo; sin embargo, más que una luz como objeto verificable que ilumina objetos preexistentes, esa línea apuntaría para el tipo de objetos que hace visible con ayuda de las enunciaciones. El segundo conjunto es el de las líneas de enunciación, cuya historicidad se comprende conjuntamente con la historicidad de las líneas de visibilidad. La visibilidad es dada por la enunciación de la disposición de los elementos o variables en el espacio estudiado. Las líneas de enunciación configuran regímenes de enunciación y pueden ser estéticos, científicos, políticos, etc. El tercer conjunto es de las líneas de fuerza. Estas generarían tensión entre puntos de las líneas de visibilidad y de enunciación, rectificándolas; accionarían idas y vueltas entre las palabras y las cosas, configurando el poder sin desligarlo del saber. Finalmente, en la descripción hecha por Deleuze, Foucault consideraría las líneas de subjetivación; líneas donde el poder o la fuerza del dispositivo se vuelven sobre sí o contra la objetivación ejercida por el dispositivo. La subjetivación sería un proceso no preestablecido, que surgiría cuando el dispositivo así lo permitiera. En ella operaría una individuación al nivel de grupos o personas, al margen de las relaciones de fuerza y de las relaciones establecidas por los saberes constituidos.

Por su parte, Agamben (2011) presenta su definición de dispositivo después de hacer una genealogía del término, intentando encontrar sus orígenes y resaltar su centralidad en el trabajo de Foucault. La lectura de Agamben sugiere que el lenguaje es el dispositivo primigenio, en el sentido de establecer, por el hecho de nombrarlas, la distribución de las cosas. Sin embargo, lo que parece ser más original en la genealogía construida por este autor desde la teología, es a relación que establece entre dispositivo y economía (como administración de la casa) a partir de la división trinitaria de Dios, por medio de la cual, Dios habría encargado al hijo la administración de las almas de los hombres. Según Agamben, esa administración sería para los griegos la oikonomia y para los latinos pasaría a ser la dispositio, término del cual derivaría el de positividad. Ésta última sería la idea opuesta a la de naturaleza retomada de Hegel por Hypolite (maestro de Foucault); y construiría el “elemento histórico, con todo ese peso de reglas, de ritos y de instituciones que están impuestos a los individuos por medio de un poder exterior, pero que se encuentra, por así decir, interiorizado en sistemas de creencias y sentimientos." (Agamben, 2011, p. 252). Así, Agamben propone un punto de encuentro entre economía, gobierno, administración y disposición-dispositivo, en los siguientes términos: 
El vínculo que reúne todos esos términos es la referencia a una economía, es decir a un conjunto de prácticas, de saberes, de medidas y de instituciones cuja meta es gestionar, gobernar, controlar y orientar -en un sentido en que sea útil- los comportamientos, los gestos y los pensamientos de los hombres. (Agamben, 2011, p. 256, resaltado nuestro)

Agamben llegará a definir el dispositivo como: "Todo aquello que tiene, de una forma u otra, la capacidad de capturar, orientar, determinar, interceptar, modelar, controlar y asegurar los gestos, las conductas, las opiniones y los discursos de los seres vivos". (Agamben, 2011, p. 257); y dirá que éste es también un "conjunto de prácticas y mecanismos (invariablemente discursivos y no discursivos, jurídicos, técnicos y militares) que tienen por objetivo enfrentar una urgencia para obtener un efecto más o menos inmediato" (Agamben, 2011, p. 254).

Finalmente, cabe resaltar que para este autor existe una semejanza entre disposición de las cosas, institución y consagración (sacrare), como formas de sacar las cosas del dominio de los humanos para entregarlas al dominio de lo divino, superior. Y, en este sentido, Agamben propone una forma de devolver las cosas al dominio de los humanos que sería la profanación de los dispositivos. Idea ésta que recuerda la cuarta línea de los dispositivos descrita por Deleuze, la línea de subjetivación.

También según Deleuze, el estudio de los dispositivos consistiría en desenredar las líneas. Siguiendo esta sugerencia y basado en la descripción que Deleuze hace de lo que sería un dispositivo, Dean (2010) propone un abordaje teórico-metodologíco que trata por separado los elementos que en la descripción más metafórica de Deleuze, aparecen enmarañados y presentados de modo más relacional, seguramente más fiel a la propia construcción foucaultiana.

A partir de la lectura de Deleuze, Dean propone estudiar los regímenes de prácticas o regímenes de gobierno abordando cuatro dimensiones diferentes, recíprocamente condicionadas, aunque relativamente autónomas, presentes en los dispositivos: (1) formas características de visibilidad como formas de ver y percibir; (2) formas distintas de pensar y cuestionar, basadas en vocabularios y procedimientos específicos de producción de verdad (básicamente diferentes ciencias); (3) formas específicas de actuar, intervenir y dirigir, hechas de formas específicas de racionalidad (expertice y 'knowhow') y apoyadas en mecanismos, técnicas y tecnologías definidas; y finalmente, (4) formas específicas de formación de sujetos, yos, personas, actores o agentes. Esta propuesta teórico-metodológica es denominada Analítica de Gobierno por Dean (2010).

Identificamos que en la lectura de Deleuze hecha por Dean, las líneas de subjetivación en cuanto formas de conducta contrarias al dispositivo quedan por fuera de la Analítica de Gobierno, pues Dean entiende la dimensión subjetiva del dispositivo como siendo cuestión de producción de subjetividades o identidades. Muñoz (2016) propone ampliar o integrar estos análisis entendiendo la dimensión subjetiva del dispositivo como compuesta tanto por producción de subjetividades, como por contraconductas, subjetivaciones o profanaciones.

La Analítica de Gobierno sería, así, la propuesta teórico-metodológica de tipo genealógico de Dean para dar inteligibilidad a los regímenes de prácticas, examinando las condiciones bajo las cuales estos nacen, son mantenidos, institucionalizados o ritualizados; o problematizados y transformados (Dean, 2010, p. 31). Podría pensarse en las formas de crítica de la población impactada por la construcción de la central Porce III como problematizaciones a las prácticas instituidas por el dispositivo de gobierno. 
Por las anteriores razones consideramos que un análisis genealógico desarrollado por medio de la Analítica de Gobierno vendría a ofrecer una mayor inteligibilidad a la "Gestión Social” del proyecto Porce III como práctica de gobierno, en medio de la cual se ejerce el poder, pero que no escapa a las críticas de aquellos sobre quienes recae tal ejercicio.

En este artículo nos proponemos presentar los análisis y resultados de abordar el plano de las técnicas de la "Gestión Social" reconstruido como el conjunto de líneas de fuerza (Deleuze, 1991), retomado bajo la denominación de techne de gobierno por Dean (2010). Este conjunto de líneas describiría mejor la instancia del poder en el trípode: saber, poder, subjetividad del que habla Foucault. Las líneas de fuerza dentro del dispositivo podrían ser entendidas como las fijadoras de las relaciones de poder, que a su vez conectan puntos y elementos del dispositivo según Deleuze (1991); constituyen la relación saber-poder hecha técnica.

Más específicamente en el ámbito del reasentamiento de población, es evidente que para los difusores del conocimiento "especializado" en la materia, la dimensión técnica es determinante. Michel Cernea, "experto" del Banco Mundial, afirma que frecuentemente los formuladores de este tipo de programas no estarían conscientes del "amplio conjunto de 'herramientas' de gestión social... [que podrían ser usadas] para movilizar la energía social y coordinar la acción bajo programas de desarrollo inducido" (Cernea, 1994, p. 8).

Por su parte, desde una postura académica-crítica, Muñoz (2013), desarrolla una analítica del poder de las estrategias de una empresa minera en Brasil, identificando el "modelo de sostenibilidad" que la empresa promueve en el territorio como la base de la dimensión técnica de esa estrategia. Análogamente, consideramos que el "Plan de Gestión Social” estudiado en esta investigación sería el instrumento principal que recoge el conjunto de técnicas usadas e instituidas por la empresa para lidiar con los efectos de la construcción de la central sobre la población; pero, sin dejar de lado otros instrumentos que ayudaron a concretar las "negociaciones", así como a "formar" y "capacitar" a los impactados para su adaptación a un nuevo entorno.

Aunque la dimensión técnica del dispositivo pueda ser entendida a partir de los modelos, planes, programas, proyectos, contratos, etc., explícitamente formulados e institucionalizados por la empresa, las informaciones de campo sugieren que la institucionalización no es condición de toda práctica realizada en el territorio. Así, es posible identificar un conjunto de prácticas no institucionalizadas usadas por la empresa. Por esta razón, presentamos a continuación tanto las formas instituidas, como las no instituidas de la dimensión técnica de la "gestión social" en la construcción de la central hidroeléctrica Porce III.

\section{Resultados}

Los instrumentos analizados a continuación fueron usados en la "gestión social" de la población impactada por la central Porce III. Éstos son definidos de forma general por el Estado colombiano en los marcos normativos del proceso de licenciamiento ambiental y especificados posteriormente por la empresa al llevar a cabo el proceso de reasentamiento de la población desplazada. Ellos presentan una definición explícita en términos de procedimientos y elementos a ser tenidos en cuenta. Se comentan algunas características de cuatro instrumentos específicos que a nuestro juicio fueron fundamentales en el proceso de "gestión" de dicha población. 


\section{E1 "Plan de Gestión Social"}

Desde un punto de vista práctico, es decir, desde las prácticas de la empresa en el territorio, el "Plan de Gestión Social” (PGS) es el instrumento que orienta las acciones en el manejo de los impactos identificados en el Estudio de Impacto Ambiental (EIA).

El Estudio de Impacto Ambiental es el instrumento que orienta el proceso de licenciamiento ambiental en Colombia. A partir de este se elaboran los Planes de Manejo Ambiental con los cuales los interesados acceden a la licencia ambiental de una determinada actividad ante la autoridad competente.

Al corresponder a la lógica de la gestión, este plan se inserta en la estructura del Plan de Manejo Ambiental (PMA) y está compuesto por una estructura de programas, proyectos y actividades. Como componente del PMA, el PGS es formulado por la empresa y sus consultores, aprobado por el Estado y, posteriormente, ejecutado mediante la subcontratación de diversas empresas de consultoría.

Presentaremos a continuación el contenido del Plan, comenzando por una breve descripción del origen de su concepción. Este plan es descrito como un ejemplo de "diseño integrado de gestión socio ambiental". Su estructura fue concebida usando la "Metodología de Marco Lógico" empleado por el banco Mundial y cuyo origen se remonta la década del sesenta, cuando fue concebida por el Departamento de Defensa de Estados Unidos, según Díaz (2010). La lógica de la metodología consiste en definir situaciones o estados deseados (que son a su vez los propósitos u objetivos de los programas) y concebir proyectos cuya ejecución respondería a los objetivos de los programas. Cada proyecto tiene unos componentes que son materializados a través de actividades. En la siguiente tabla se muestra la estructura del plan.

Tabla 1. Estructura del Plan de Gestión Social Porce III.

\begin{tabular}{|c|c|c|c|}
\hline Programa & $\begin{array}{l}\text { Propósito } \\
\text { (objetivo) }\end{array}$ & Proyecto & Componente / resultado \\
\hline \multirow{10}{*}{$\begin{array}{l}\text { Restitución de } \\
\text { las } \\
\text { condiciones } \\
\text { de vida de la } \\
\text { población a } \\
\text { ser desplazada }\end{array}$} & \multirow{10}{*}{$\begin{array}{l}\text { Condiciones de } \\
\text { vida (hábitat, base } \\
\text { económica y redes } \\
\text { sociales y culturales) } \\
\text { de la población con } \\
\text { derechos restituidas, } \\
\text { a través de procesos } \\
\text { participativos y de } \\
\text { decisiones } \\
\text { concertadas entre } \\
\text { las familias, } \\
\text { organizaciones } \\
\text { comunitarias, } \\
\text { administraciones } \\
\text { municipales y EPM, }\end{array}$} & \multirow[t]{5}{*}{ Reubicación } & $\begin{array}{l}\text { Acompañamiento Social pre- } \\
\text { traslado concluído. }\end{array}$ \\
\hline & & & $\begin{array}{l}\text { Vivienda y servicios públicos } \\
\text { restituidos. }\end{array}$ \\
\hline & & & Infraestructura social restituida \\
\hline & & & Base económica restituida \\
\hline & & & $\begin{array}{l}\text { Redes sociales y culturales } \\
\text { reestablecidas }\end{array}$ \\
\hline & & \multirow[t]{5}{*}{ Relocalización } & $\begin{array}{l}\text { Acompañamiento Social pre- } \\
\text { traslado concluido. }\end{array}$ \\
\hline & & & $\begin{array}{l}\text { Vivienda y servicios públicos } \\
\text { restituidos. }\end{array}$ \\
\hline & & & Infraestructura social restituida \\
\hline & & & Base económica restituida \\
\hline & & & $\begin{array}{l}\text { Redes sociales y culturales } \\
\text { reestablecidas }\end{array}$ \\
\hline
\end{tabular}




\begin{tabular}{|c|c|c|c|}
\hline & $\begin{array}{l}\text { en el marco de la } \\
\text { legislación vigente. }\end{array}$ & Compra directa & $\begin{array}{l}\text { Acompañamiento social para la } \\
\text { concertación concluido. }\end{array}$ \\
\hline & & & $\begin{array}{l}\text { Monitoreo de las condiciones } \\
\text { socioeconómicas en la fase de } \\
\text { construcción concluido. }\end{array}$ \\
\hline \multirow[t]{9}{*}{$\begin{array}{l}\text { Convivencia } \\
\text { Porce III - } \\
\text { región }\end{array}$} & \multirow{9}{*}{$\begin{array}{l}\text { Convivencia entre el } \\
\text { proyecto } \\
\text { Hidroeléctrico Porce } \\
\text { III y los actores } \\
\text { sociales del área de } \\
\text { influencia } \\
\text { fortalecida, a través } \\
\text { de la participación y } \\
\text { toma de decisiones } \\
\text { de intervención } \\
\text { concertadas entre } \\
\text { las comunidades, } \\
\text { organizaciones } \\
\text { comunitarias, } \\
\text { administraciones } \\
\text { municipales y } \\
\text { EPM, en el marco de } \\
\text { la legislación vigente. }\end{array}$} & $\begin{array}{l}\text { Acompañamiento } \\
\text { a la presión } \\
\text { migratoria }\end{array}$ & $\begin{array}{l}\text { Monitoreo del grado de incidencia } \\
\text { de Porce III en el flujo migratorio } \\
\text { del área de influencia y en el } \\
\text { aumento de la demanda de } \\
\text { servicios públicos y sociales } \\
\text { concluido }\end{array}$ \\
\hline & & \multirow{3}{*}{$\begin{array}{l}\text { Apoyo al } \\
\text { fortalecimiento } \\
\text { de las } \\
\text { organizaciones } \\
\text { comunitarias }\end{array}$} & $\begin{array}{l}\text { Acompañamiento para el cierre de } \\
\text { las organizaciones comunitarias } \\
\text { concluido }\end{array}$ \\
\hline & & & $\begin{array}{l}\text { Área de gestión y proyección } \\
\text { interna desarrollada y fortalecida. }\end{array}$ \\
\hline & & & $\begin{array}{l}\text { Área de gestión y proyección } \\
\text { externa desarrollada y fortalecida. }\end{array}$ \\
\hline & & \multirow[t]{3}{*}{$\begin{array}{l}\text { Articulación a la } \\
\text { gestión municipal }\end{array}$} & $\begin{array}{l}\text { Comités intermunicipales y talleres } \\
\text { de trabajo realizados. }\end{array}$ \\
\hline & & & $\begin{array}{l}\text { Proyecto Porce III articulado con } \\
\text { los planes de desarrollo municipal } \\
\text { (PDM) y Esquemas de } \\
\text { Ordenamiento Territorial (EOT). }\end{array}$ \\
\hline & & & $\begin{array}{l}\text { Administraciones municipales y } \\
\text { organizaciones de desarrollo } \\
\text { comunitario informadas sobre la } \\
\text { procedencia y manejo de los } \\
\text { recursos de las leyes } 56 \text { y } 99 .\end{array}$ \\
\hline & & \multirow{2}{*}{$\begin{array}{l}\text { Acompañamiento } \\
\text { de las } \\
\text { condiciones } \\
\text { socioeconómicas } \\
\text { de las } \\
\text { comunidades del } \\
\text { área de influencia }\end{array}$} & $\begin{array}{l}\text { Caracterización de las comunidades } \\
\text { del área de influencia actualizadas } \\
\text { cada } 2 \text { años. }\end{array}$ \\
\hline & & & $\begin{array}{l}\text { Identificación y evaluación de } \\
\text { impactos socioeconómicos } \\
\text { actualizados cada } 2 \text { años. }\end{array}$ \\
\hline Comunicación & $\begin{array}{l}\text { Familias, } \\
\text { organizaciones } \\
\text { comunitarias, } \\
\text { administraciones } \\
\text { municipales y demás }\end{array}$ & $\begin{array}{l}\text { Producción de } \\
\text { medios y material } \\
\text { promocional }\end{array}$ & $\begin{array}{l}\text { Producción y difusión de medios } \\
\text { informativos sobre los avances en } \\
\text { la construcción y en la gestión } \\
\text { socio ambiental de Porce III } \\
\text { concluidos. }\end{array}$ \\
\hline
\end{tabular}




\begin{tabular}{|c|c|c|}
\hline \multirow{13}{*}{$\begin{array}{l}\text { partes interesadas } \\
\text { informadas y } \\
\text { participando en los } \\
\text { espacios } \\
\text { comunicativos } \\
\text { relacionados con el } \\
\text { proyecto Porce III. }\end{array}$} & \multirow[t]{10}{*}{$\begin{array}{l}\text { Comunicación } \\
\text { con partes } \\
\text { interesadas }\end{array}$} & $\begin{array}{l}\text { Espacios de comunicación con } \\
\text { comunidades del área de influencia } \\
\text { en funcionamiento. }\end{array}$ \\
\hline & & $\begin{array}{l}\text { Espacios de comunicación con } \\
\text { familias reubicadas y relocalizadas } \\
\text { en funcionamiento. }\end{array}$ \\
\hline & & $\begin{array}{l}\text { Espacios de comunicación con } \\
\text { organizaciones comunitarias en } \\
\text { funcionamiento. }\end{array}$ \\
\hline & & $\begin{array}{l}\text { Espacios de comunicación con } \\
\text { administraciones municipales en } \\
\text { funcionamiento. }\end{array}$ \\
\hline & & $\begin{array}{l}\text { Espacios de comunicación con } \\
\text { funcionarios y directivos de EPM } \\
\text { en funcionamiento. }\end{array}$ \\
\hline & & $\begin{array}{l}\text { Espacios de comunicación con } \\
\text { entidades del Estado en } \\
\text { funcionamiento. }\end{array}$ \\
\hline & & $\begin{array}{l}\text { Espacios de comunicación con el } \\
\text { Banco Interamericano de } \\
\text { Desarrollo en funcionamiento }\end{array}$ \\
\hline & & $\begin{array}{l}\text { Espacios de comunicación con } \\
\text { medios de comunicación regionales } \\
\text { y nacionales en funcionamiento. }\end{array}$ \\
\hline & & $\begin{array}{l}\text { Espacios de comunicación con } \\
\text { ONG y universidades antioqueñas } \\
\text { en funcionamiento. }\end{array}$ \\
\hline & & $\begin{array}{l}\text { Espacios de comunicación con } \\
\text { empresas del sector eléctrico en } \\
\text { funcionamiento. }\end{array}$ \\
\hline & \multirow[t]{3}{*}{$\begin{array}{l}\text { Comunicación } \\
\text { para la } \\
\text { participación }\end{array}$} & $\begin{array}{l}\text { Memoria cultural de las } \\
\text { comunidades del área de influencia } \\
\text { socializada. }\end{array}$ \\
\hline & & $\begin{array}{l}\text { Niños, jóvenes y adultos de las } \\
\text { familias desplazadas y receptoras } \\
\text { fortalecidos en sus habilidades } \\
\text { comunicativas. }\end{array}$ \\
\hline & & $\begin{array}{l}\text { Miembros de organizaciones } \\
\text { comunitarias fortalecidos en sus } \\
\text { habilidades comunicativas. }\end{array}$ \\
\hline
\end{tabular}




\begin{tabular}{|c|c|c|c|}
\hline \multirow[t]{10}{*}{$\begin{array}{l}\text { Educación } \\
\text { ambiental }\end{array}$} & \multirow{10}{*}{$\begin{array}{l}\text { Familias, } \\
\text { comunidades e } \\
\text { instituciones } \\
\text { educativas del área de } \\
\text { influencia de Porce } \\
\text { III formadas en la } \\
\text { conservación, } \\
\text { mejoramiento, } \\
\text { recuperación y uso } \\
\text { sostenible de su } \\
\text { entorno. }\end{array}$} & \multirow[t]{3}{*}{$\begin{array}{l}\text { Educación } \\
\text { ambiental con } \\
\text { grupos familiares }\end{array}$} & $\begin{array}{l}\text { Familias capacitadas en manejo } \\
\text { integral de residuos sólidos, } \\
\text { residuos líquidos, microcuencas y } \\
\text { biodiversidad. }\end{array}$ \\
\hline & & & $\begin{array}{l}\text { Familias con prácticas } \\
\text { agropecuarias y de comercio y } \\
\text { servicios sostenibles en } \\
\text { funcionamiento. }\end{array}$ \\
\hline & & & $\begin{array}{l}\text { Sistemas de MIRS en } \\
\text { funcionamiento. }\end{array}$ \\
\hline & & \multirow[t]{3}{*}{$\begin{array}{l}\text { Autogestión } \\
\text { ambiental } \\
\text { comunitaria }\end{array}$} & $\begin{array}{l}\text { Comunidades del área de influencia } \\
\text { de Porce III fortalecidas en el ciclo } \\
\text { de gestión de proyectos } \\
\text { ambientales. }\end{array}$ \\
\hline & & & $\begin{array}{l}\text { Fuentes de agua adoptadas por las } \\
\text { comunidades }\end{array}$ \\
\hline & & & $\begin{array}{l}\text { Entorno comunitario mejorado } \\
\text { ambientalmente mediante la } \\
\text { protección de fuentes de agua y } \\
\text { delimitación de protección de } \\
\text { bosques con participación } \\
\text { comunitaria }\end{array}$ \\
\hline & & \multirow[t]{4}{*}{$\begin{array}{l}\text { Apoyo a la } \\
\text { educación } \\
\text { ambiental escolar }\end{array}$} & $\begin{array}{l}\text { Ejecutores del programa de } \\
\text { educación ambiental capacitados } \\
\text { en Proyectos Ambientales } \\
\text { Escolares (PRAES) }\end{array}$ \\
\hline & & & Maestros capacitados en PRAES \\
\hline & & & $\begin{array}{l}\text { PRAES de las instituciones } \\
\text { educativas del área de influencia } \\
\text { formulados }\end{array}$ \\
\hline & & & $\begin{array}{l}\text { PRAES de las instituciones } \\
\text { educativas del área de influencia en } \\
\text { funcionamiento. }\end{array}$ \\
\hline
\end{tabular}

Fuente: Diaz (2010, p. 189-192).

A continuación, se presenta una breve descripción de los programas que conformaron el plan, comentando la evaluación retrospectiva hecha por Gómez (2010) en el texto Desarrollo Social con Energía, sobre la "gestión social" en Porce III, en su condición de director ejecutivo de la empresa operadora que implementó dicho plan; así como de la banca multilateral financiadora. 
Programa de restitución de las condiciones de vida: según Gómez (2010) este programa pretendía que "las condiciones de vida que las familias tenían, fueran restituidas de manera integral en su nuevo entorno y mejoradas, como consecuencia de las obras de desarrollo". Este autor enfatiza la necesidad de capacitación de las familias para su adaptación al nuevo entorno, buscando garantizar la seguridad social de las poblaciones en su nuevo hábitat, teniendo presente el carácter transitorio de este acompañamiento de la adaptación de las familias, que serían seguidamente vinculadas a la "gestión social municipal" para "no generarles dependencia" de la empresa. Igualmente, se hablaba también de una meta de "auto sostenibilidad".

Para lograr el propósito de la restitución de las condiciones de vida, el programa se divide en tres proyectos que son la reubicación, la relocalización, que implican un acompañamiento técnico a cada una de las familias hasta su auto sostenibilidad; y la compra directa que solo contempla el monitoreo (Gómez, 2010, p. 184, resaltado nuestro).

Según el informe de la Gestión Ambiental y Social del Banco Interamericano de Desarrollo financiador parcial de la central-, las medidas compensatorias para los 957 impactados (582 familias y 375 mineros - datos del trabajo: "Fortalecer la identidad con el territorio de 61 familias reasentadas de la central hidroeléctrica Porce III en zona rural de los municipios de Guadalupe y Anorí del departamento de Antioquia" (texto no publicado)- fueron la compensación directa, la reubicación y la relocalización. Veamos los diferentes sentidos de esas medidas.

Compensación directa: más comúnmente denominada y presentada a la población como "compra directa”, consistía en: “... el proceso de valorar los activos físicos y los aspectos económicos y sociales de las familias. Se compensa la vivienda, como mínimo, con el criterio de unidad mínima familiar, los anexos o mejoras, el reconocimiento por la actividad económica, los aspectos de vulnerabilidad y el factor de desplazamiento que sufren los propietarios desplazados". A esta medida adhirieron 787 impactados, entre familias y mineros, aproximadamente el 82\% de población total afectada.

La medida de reubicación es definida en el informe como: "traslado de un grupo familiar a un territorio con características similares a las de su medio habitual, localizado en la zona del proyecto en las localidades vecinas de los municipios de Amalfi, Anorí, Guadalupe y Gómez Plata”. Un total de 72 familias optaron por esta medida, es decir, un aproximado de 8\% del total de la población afectada. Esta medida estaba representada básicamente por el establecimiento de proyectos agropecuarios de cría de ganado, especies menores, cultico de café y/o cacao y cultivos de transitorios, así como la restitución de la vivienda.

Por su parte la relocalización fue definida como: "el traslado de un grupo familiar del área de influencia del proyecto para las áreas urbanas de los municipios de área de influencia (Amalfi, Anorí, Gómez Plata y Guadalupe), o para veredas que no son del área de influencia del proyecto"; igualmente, con restitución de la vivienda. Un total de 98 familias aceptó esta medida, lo que equivalía a un aproximado de $10 \%$ del total. Se incluían aquí proyectos agropecuarios en las zonas rurales y de comercio y servicios en las áreas urbanas. Algunos proyectos en esta última modalidad eran tiendas de abarrotes, restaurantes, servicios de transporte, comunicaciones, etc., algunos de los cuales fueron incluso establecidos en zonas urbanas de municipios más distantes, como Yolombó y Barbosa. 
El acompañamiento a las familias desplazadas que optaron por proyectos de comercio y servicios o proyectos agropecuarios se basó en un proceso de "capacitación" colectiva y de visitas domiciliarias de "fonación y seguimiento" en los temas relacionados con el nuevo entorno y las actividades de las familias: actividad económica, redes sociales, aspectos familiares, aspectos ambientales, comunitarios y de relacionamiento don las administraciones municipales.

Programa Convivencia Porce III-Región: este programa correspondió a la necesidad de generar un ambiente favorable a la empresa en el territorio, lo que se infiere, además, del término "convivencia" que le da nombre. Este programa tuvo como objetivos, entre otros, el manejo de los impactos por presión migratoria generada por el proyecto sobre el territorio.

Vainer y Araújo (1992) hablan de la Inserción regional de las empresas del sector energético brasileño, mostrando como las empresas desconsiderarían a las comunidades aguas abajo de la represa, pues ellas, al no ser desplazadas, “... no presencian la construcción de la obra, no están advertidas de los riesgos que corren, y no representan, por lo tanto, ninguna resistencia u obstáculo efectivo al proyecto" (Vainer y Araújo, 1992, p. 58, traducción nuestra). Esta concepción registrada por esa investigación de los años 80 en Brasil parecería estar superada en el caso de Porce III, toda vez que varias veredas de aguas abajo de la represa fueron incluidas como veredas del área de influencia directa e incluidas en los programas de la gestión social, aunque únicamente en aquellos temas sobre prevención de desastres.

Los proyectos incluidos en este programa fueron: "monitoreo a la presión migratoria, apoyo al fortalecimiento de la organización comunitaria, articulación a la gestión municipal y acompañamiento a las condiciones socioeconómicas de las comunidades del área de influencia” (Gómez, 2010, p. 185). Estos contenidos evidencian una gran semejanza entre el tratamiento propuesto por la empresa para los impactos sobre las familias y el propuesto para las organizaciones comunitarias de la región impactada. A las organizaciones se le invitaba a un involucramiento informado, con mayores niveles de capacitación y formación de "capital social", con el objetivo de desarrollar una co-gestión entre empresa, comunidad y administraciones municipales. En el primer caso, el de las familias, se dio énfasis a las capacitaciones personales y sicológicas; mientras que, en el nivel comunitario, se enfatizó en la formación de capacidades para la "proyección interna y externa" de la organización comunitaria.

Cabe anotar que esta noción de "capital social", como un atributo a ser promovido en las comunidades y grupos pobres para mejorar su capacidad organizativa hacia el desarrollo y la democracia (Banco Mundial, citado en Arriagada, 2003), es parte de la visión de "gobernanza" de la banca multilateral, visión criticada por autores como Acselrad (2002) por "subordinar la salud de la población a la salud de los bancos y la sostenibilidad del medio ambiente a la sostenibilidad de los flujos financieros especulativos" (p. 21, traducción nuestra).

Programa de Comunicación. Las estrategias y actividades de comunicación fueron de tal importancia para la empresa, que uno de los cuatro programas del PGS fue dedicado exclusivamente a esta área. Gracias a esa importancia asignada, las actividades y "productos" de este programa eran estrictamente controlados por el respectivo departamento de la empresa matriz y se articulaban a una estrategia mayor de comunicaciones. Un importante volumen de información fue producido y comunicado a través de este programa, por diferentes medios: escritos, visuales, radiales, en reuniones 
con las comunidades, etc.; dando énfasis a los resultados de las acciones de la empresa que eran periódicamente publicados en la región y también comunicados a públicos más amplios, a través del portal electrónico.

Gómez (2010) describe los objetivos de la "estrategia de comunicación” en términos que resuenan con el leguaje de la banca multilateral al hablar de lasos comunitarios, generación de condiciones de participación, etc:

... garantizar la información a las comunidades de influencia directa e indirecta y a las autoridades e instituciones locales sobre todos sus componentes, que propicien los lasos de interacción comunitaria y alcanzar el reconocimiento, identificación y apropiación de los grupos sociales y [...] la generación de las condiciones para la participación formada e informada de los diferentes actores sociales e institucionales en los espacios de comunicación y gestión propiciados para la construcción de proyecto hidroeléctrico (Gómez, 2010, p. 185, resaltado nuestro).

También según el BID, este programa definiría los medios de información interna y externa a los diferentes "grupos de interés [y] permitiría a las comunidades participar de una manera informada y consistente" (BID, 2005, p. 48). Por su parte, EPM lo define como una "estrategia de gestión del PMA" que busca el "manejo de las expectativas de la población" para "garantizar la armonía entre los intereses de parte y parte" (EPM, 2002, p. 211-212).

Sin embargo, más allá de esta descripción oficial del programa y de sus objetivos, las actividades de comunicación de las empresas constituyen los espacios por excelencia para el ejercicio de lo que podríamos llamar, en los términos de Bourdieu (2013, p. 63-64) de "violencia simbólica", violencia según la cual, formas de percepción compatibles con condiciones objetivas desiguales tienen éxito en instalarse en los agentes mediante el uso de una comunicación disimulada o eufemística de esas condiciones objetivas.

Fue posible identificar algunas inconformidades de la población impactada con algunas actividades de la estrategia de comunicación, más específicamente con las entrevistas grabadas por la empresa y del equipo de la "gestión social" a las familias reasentadas y con el manejo de la información de dichas entrevistas. El siguiente testimonio de un líder comunitario reasentado por el proyecto ilustra tal malestar:

(...) Mis hijos se engancharon en la empresa y han aprendido a manejar retroexcavadora en la empresa, y han pasado por varios proyectos, eso es una cosa buena del proyecto... Pero nunca vi eso como una colaboración, sino como un derecho. Por eso cuando me visitaban, yo no daba pantallazos a su favor, yo decía lo legal... No me gustó fue que una vez vinieron y me hicieron una entrevista y sacaron unos afiches diciendo que yo estaba muy contento y que EPM se estaba manejando muy bien con todo el mundo, y en Amalfi me preguntaban y yo dije, eso no es cierto, eso no es cierto... a mí me tomaron esa entrevista y yo no sabía para qué (...) (Entrevista)

Otros problemas son la información manifestados por la población son analizados en la siguiente sección sobre las tácticas no instituidas. 
Programa de Educación Ambiental: la educación ambiental adquirió estatus de programa en el Plan. Como en otros programas de educación ambiental tanto de empresas, como de instituciones educativas, es común la tendencia a colocar en la población el déficit de educación y/o consciencia ambiental, déficit que el programa pretende entonces remediar. El programa de educación ambiental del proyecto Porce III tenía como objetivo: “aportar a la creación de las condiciones de sostenibilidad ambiental para la región en tres niveles, correspondientes a tres proyectos: "Educación ambiental escolar, Educación ambiental con familias reasentadas y Educación ambiental comunitaria" (Gómez, 2010).

Las actividades de educación ambiental con familias fueron realizadas tanto en espacios colectivos, como en los respectivos lugares de reasentamiento de las familias. El trabajo de educación ambiental escolar fue tercerizado por medio de la contratación de una universidad pública y tuvo como objetivo incluir las directrices de la política de educación ambiental del país en las estructuras curriculares de las instituciones educativas rurales localizadas en el área del proyecto. Es importante anotar que, por solicitud del equipo de gestión social de la empresa operadora del PGS, instituciones educativas que no estaban en el área definida como de influencia directa por la empresa, fueron también incluidas para ser, como solía decirse "beneficiarias" del programa.

La educación ambiental promovida por la empresa se enmarcó en lo que se conoce como educación ambiental comportamental o conservadora que opera mediante una psicología de la consciencia (Carvalho, 2001). Una corriente dominante dentro de los abordajes de educación ambiental, que se desarrolla paralelamente con los discursos de la sostenibilidad que no tienen en cuenta el poder y los conflictos del sistema productivo que produce la degradación ambiental que es tipo de educación quiere corregir. Así, las familias y comunidades "educadas ambientalmente" por el proyecto Porce III eran instruidas para cambiar sus comportamientos que podían afectar el entorno, como la quema de residuos sólidos, la quema y corte de vegetación en las orillas de las quebradas, etc.; así como para incorporar nuevos comportamientos, como el mantenimiento de los sistemas sépticos de las viviendas. Aunque estas orientaciones puedan tener fines deseables, nunca se puso en discusión la magnitud de los danos ambientales producidos por la empresa -que asume el papel de educadora-, con relación a los danos al entorno que la educación ambiental pretendía evitar al cambiar los comportamientos de los impactados por la central- los educandos.

Una revisión del portal electrónico de otro de los proyectos, construido en Colombia, la central hidroeléctrica El Quimbo, a cargo de la empresa multinacional Emgesa, evidencia que las empresas del sector están pensando y actuando en términos similares para el cumplimiento de los requisitos legales y para la legitimación de sus proyectos; usando racionalidades explicitadas en configuraciones programáticas parecidas. Un paralelo con el PGS analizado en este trabajo es llamado por esa empresa de "Plan de Gestión Socioeconómico y Cultural".

Composición del "Plan de Gestión socioeconómico y cultural" Emgesa (2016): Programa de información y participación, programa de reasentamiento de la población, programa de restitución de la infraestructura física, programa de empleo temporal y prestación de servicios durante la construcción de la central, programa para el desarrollo de la actividad pesquera en el embalse (durante la operación), programa de fortalecimiento institucional, programa de saneamiento y la salud de los 
trabajadores de la central, programa de traslado y restitución del patrimonio cultural, programa de arqueología preventiva, programa de seguimiento para la prestación de los servicios sociales en el área vecina del embalse, programa de educación ambiental, programa de restitución de empleo, programas para la restitución de la actividad productiva en el área de influencia directa. (Emgesa, 2016)

\title{
El "Manual de Valores Unitarios"
}

\begin{abstract}
Algunos asuntos, como la restitución de la base económica, se deben ajustar a las reglas del mercado, mientras otros, como el fortalecimiento de la organización comunitaria deberían ser liderados por la sociedad (Díaz, 2010, p. 86, resaltado nuestro).
\end{abstract}

Como instrumento para el cálculo de las compensaciones e indemnizaciones y como tecnología de valoración de los bienes de los impactados generados por la central, la empresa lideró la elaboración de un "Manual de Valores Unitarios" que, como su nombre lo indica, contiene los precios por unidad para la conversión monetaria de los bienes de las familias, sus tierras, mejoras y sistemas y actividades productivas. La valoración fue efectuada con el establecimiento de un conjunto de características genéricas de los bienes como: tipo de material de construcción de las casas, tipo de suelo de las tierras, tipo de pastos sembrados, etc. Para cada tipo de bien fue asignado un costo por unidad que fue calculado según su respectivo mercado local.

Para la elaboración de este instrumento, según está previsto en la ley colombiana, se designó una comisión tripartita compuesta por un representante de la empresa, un representante del Estado y un representante de la población impactada. La participación de la población en la definición de esos precios o valores unitarios de las tierras, los cultivos, animales, etc., se dio de forma representativa, razón por la cual ellos se vieron instados a elegir a alguien de la comunidad para tal fin.

Este sería el instrumento por excelencia de interacción entre empresa y comunidades impactadas en el plano de los intercambios monetarios. La valoración del tipo monetario de los bienes de las poblaciones impactadas muestra una fuerza y carácter de necesidad que impone su realidad a los actores. Esta fuerza proviene, de un lado, del poder de institución conferido por el Estado como "sede por antonomasia de concentración del poder simbólico" (Bourdieu, 2007, p. 108), poder que es transferido a la empresa en la medida en que ella se encarga de coordinar la elaboración del mencionado manual. De esta manera, Estado y empresa consiguen imponer una forma de interacción social coherente con sus estructuras organizacionales y saberes técnicos. El saber de los técnicos involucrados, proveniente las ciencias contables, administrativas, económicas, financieras, etc., sería lo que confiere la otra fuente de poder a este mecanismo de valoración monetaria de los bienes e “impactos". No es en vano que la empresa disponga de una "Unidad de Negociación y Administración de Activos Inmobiliarios” y de un grupo de funcionarios formados en estas áreas del conocimiento que representan a la empresa en su interacción con las comunidades.

\section{El "Contrato de reasentamiento"}

El instrumento que mejor representa el proceso de objetivación de las relaciones de poder establecidas en el proceso de reasentamiento de la población en la construcción de la central Porce III es el denominado "contrato de reasentamiento". Este contrato era firmado entre un representante de la empresa y cada familia o persona impactada y delimitaba las responsabilidades legales que cabían a 
la empresa. Una parte de uno de los contratos entre la empresa y una familia reasentada se presenta en la siguiente figura:

Figura1. Primera página de un "contrato de reasentamiento" del Proyecto Porce III.

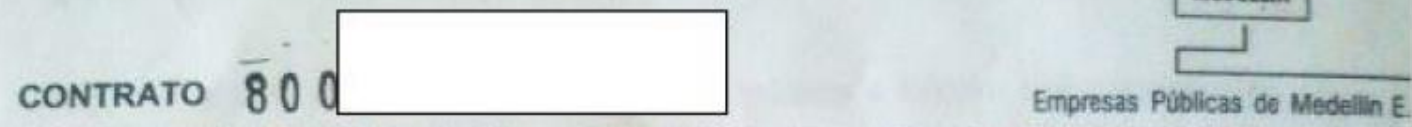

CON MEDIDA DE RESTITUCIÓN - REUBICACIÓN PARA EL DESARROLLO DEL PROYECTO HIDROELÉCTRICO PORCE III DE LAS EMPRESAS PÚBLICAS DE MEDELLIN E.S.P.

- COMPENSACIÓN POR ACTIVIDAD ECONÓMICA: $\$ 29, \square$

- PROYECTO ECONÓMICO \$57,

- RESTITUCIÓN DE VIVIENDA: TIPO 2

- benEFICIARIO:

- VALOR total \$57,

Entre los suscritos: vecino de Medellin, identificado con la cédula de ciudadanía No. $\square$ expedida en Medellin, en su condición de Subdirector de Logistica, según delegación otorgada por el Gerente General, mediante Decreto 1559 de febrero 1 de 2006, y por tanto en nombre y representación de las Empresas Públicas de Medellin E.S.P., Empresa Industrial y Comercial del Estado del orden municipal, con personeria juridica y patrimonio independiente, con domicilio principal en esta ciudad, oreada por el Acuerdo No. 58 del 6 de agosto de 1955 del Consejo Administrativo de Medellin, y transformada por el acuerdo No. 69 expedido el 10 de diciembre de 1997 por el Concejo Municipal y publicado el 24 de diciembre del mismo año, que en lo sucesivo se denominará LAS EMPRESAS y vecino del municipio de Guadalupe, Vereda Puente Acacias, identificado con la cédula de ciudadanía $\square$ expedida en Amalfi, quien obra en nombre propio, y en adelante se denominará EL BENEFICIARIO, se ha celebrado el contrato para el pago de una compensación por actividad económica y la medida de restitución de REUBICACIÓN, contenido en las siguientes cláusulas: PRIMERA: Antecedentes: a) El Proyecto Hidroeléctrico Porce III, fue aprobado mediante Resolución No. 18-1638 del 12 de diciembre de 2003 por el Ministerio de Minas y

Fuente: EPM (2006)

Varias son las observaciones que pueden hacerse a partir de este documento. En primer lugar, en él queda explícita la denominación de los impactados como "beneficiarios" por parte de la empresa. Este lenguaje legitimador se suma a la referencia hecha en los "antecedentes" del contrato a la

\begin{tabular}{l|l|l|l|l|l|l} 
AGO.USB & Medellín - Colombia & Vol. 17 No. 2 & PP 324 - 613 & Julio - diciembre & 2017 & ISSN: 16578031
\end{tabular}


"declaratoria de utilidad pública e interés social" del proyecto. Aun así, la empresa reconoce en este documento haber causado un impacto sobre el "beneficiario" y la necesidad de compensarlo. Esta compensación, sim embargo, sería hecha según la lógica del "manual de valores unitarios", cuyo supuesto es la posibilidad de cuantificación y monetarización de todos los elementos que componen la vida del individuo o familia impactados.

Como segundo elemento, la empresa se compromete a compensar al impactado por la pérdida de la actividad económica que éste ejercía, por medio de un "proyecto productivo", así como a restituir su vivienda según la "caracterización socioeconómica” hecha por el operador de la "Gestión Social". El impactado se compromete, en ese contrato, a recibir los recursos de la indemnización para el establecimiento del proyecto productivo de la manera determinada por el operador.

Un aspecto relevante de este contrato es el compromiso que los afectados asumen de no vender sus bienes muebles, inmuebles y equipos entregados por la empresa para el desarrollo del proyecto productivo. Esta medida, además de intentar proteger el patrimonio entregado a las familias reasentadas, como era argumentado por la empresa frente a la población, tenía como objetivo garantizar la estadía de los reasentados en el nuevo entorno, garantizando así la consecución de los objetivos del PGS.

El punto que delimitaba el alcance de responsabilidad de la empresa para con el impactado firmante era la $9^{a}$ cláusula del contrato, según la cual, "el beneficiario... renuncia de forma categórica a toda reclamación posterior y acepta como definitivo y único este pago". Esta intención de delimitar y finalizar las obligaciones de la empresa con cada impactado al establecer el valor total del "contrato de reasentamiento" definía un "costo" social y por la vía de la firma de este documento buscaba evitar un "re-costo" (Pinto, 2013) proveniente de futuros conflictos con relación al pago de indemnizaciones.

Finalmente, en la última cláusula del documento, el impactado renunciaba también a ejercer la actividad de barequeo en el área de influencia del proyecto y aceptaba los términos de la "negociación" con la empresa y se sometía a las condiciones de conducta que supuestamente contribuirían para garantizar un reasentamiento exitoso.

\section{El "Plan de Formación Integral"}

Como último instrumento, Plan de Formación Integral (PFI) - Documento no disponible para consulta pública. Fue el nombre que adquirió la propuesta de "formación" y "capacitación" de la población reasentada, es decir, aquellos que recibieron compensaciones que incluían recurso para la implementación de proyectos productivos en las modalidades agropecuaria o de comercio y servicios. La mayor parte de esta población tenía como actividad principal la extracción de oro del río y como actividades complementarias la agricultura y cría de animales. Esto implicó un cambio en la actividad productiva, y para eso, un aprendizaje inducido por el proceso de "acompañamiento".

El proceso de "formación” fue desarrollado por medio de talleres de capacitación colectiva y visitas domiciliarias en las fincas o locales comerciales, según el proyecto productivo seleccionado en cada caso. Las temáticas abarcaban una amplia gama de aspectos relacionados con: cambios en los estilos de vida, actividades productivas, concepción y relación con el dinero y la propiedad, relaciones con el entorno, etc., y los talleres y visitas eran conducidos por los mismos técnicos de las diferentes áreas que conformaban el equipo de la empresa operadora de la "gestión social". 
Aunque el documento titulado Plan de Formación Integral (EPM, 2006) no enuncie explícitamente el objetivo del plan, se infiere de los resultados esperados, que este tenía como propósitos: proporcionar los elementos necesarios para que las familias establezcan su actividad económica y tengan una actitud favorable al cambio y una adaptación adecuad a la nueva realidad; aumentar la capacidad de las familias desplazadas para desarrollar tecnologías agropecuarias; fortalecer la capacidad técnica y operativa de las familias desplazadas para conservar, mejorar y usar de forma sostenible su entorno; y fomentar la adaptación económica y sociocultural al nuevo hábitat.

La metodología usada, según el documento consultado era la Reflexión Acción Participación (RAP), definida como una metodología que: "permite a los sujetos construir conocimiento más profundo de su realidad individual, social y cultural, comprenderla y reconocerse en ella para orientar acciones para su trasformación” (EPM, 2006, p. 10). Aunque esta metodología se proponía considerar los conocimientos previos de los participantes sobre actividades agropecuarias, ella no tuvo en cuenta la principal actividad que por tradición esta población ejercía en el territorio, la minería tradicional. Así, el PFI operó como una forma de borrar esa parte del saber tradicional para instaurar y consolidar un saber de acuerdo con las necesidades de la central hidroeléctrica y del mismo Estado. El PFI se implementó como "eje transversal" de asistencia técnica para la "transferencia de conocimiento" sobre la administración y operación de los proyectos productivos; el acompañamiento social para la "aceptación del duelo" y adaptación al cambio, el restablecimiento de las redes sociales y la motivación en relación al nuevo proyecto de vida.

\section{Programa de monitoreo}

Un último instrumento que comentaremos es el denominado "Programa de Monitoreo del Desempeño" de las familias y comunidades. Este programa buscaba hacer seguimiento al proceso de incorporación de técnicas, conocimiento y prácticas promovida por la "Gestión Social". Por su parte, los resultados de este monitoreo eran usados por la empresa operadora de la GS para rendir cuentas ante la empresa dueña del proyecto, la cual a su vez los usaba para publicitar su intervención en el territorio, cuando los resultados eran satisfactorios.

El programa de monitoreo definía metas para cada componente de cada programa del PGS. Para ello, establecía variables a ser medidas e índices que agrupaban esas variables. Mediante la medición semestral de tales variables y el procesamiento de los índices, se componía una "curva de desempeño" para cada aspecto evaluado. Así, por ejemplo, en educación ambiental se establecieron tres índices de desempeño, uno para cada proyecto que componía el programa: índice de desempeño ambiental familiar, índice de desempeño ambiental escolar e índice de desempeño ambiental comunitario. En el caso de las familias, por ejemplo, el instrumento de monitoreo incluía los siguientes temas para la conformación de Índice de Desempeño Ambiental Familiar (IDAF): separación de residuos sólidos, producción de abonos orgánicos, mantenimiento de sistema séptico, realización de quemas antes del cultivo, desperdicio de agua en los potreros, diversificación de cultivos, etc. Un total de 40 variables componían el índice, cuya evaluación producía resultados entre cero y 100. A cada nueva visita de monitoreo, los resultados de la medición anterior eran socializados con cada familia buscando el reconocimiento de los aspectos por mejorar antes de la próxima medición del índice. De la misma forma, los otros proyectos del programa eran también monitoreados. Índices de desempeño eran 
también construidos y medidos para el aspecto económico de las familias y de organización de las comunidades en los nuevos reasentamientos.

De los instrumentos técnicos instituidos como parte del proceso de reasentamiento pasaremos a una breve revisión de las prácticas no instituidas, pero que igualmente, tuvieron un papel estratégico en la consecución de los objetivos de la empresa.

\section{Prácticas no instituidas}

La información de campo muestra que no todas las prácticas de la empresa se redujeron o limitaron a los formatos instituidos. Así como en los casos de las empresas de generación de energía eléctrica en Brasil, analizados por Vainer y Araújo (1990), en Porce III se evidenció una desinformación estratégica, una negociación individualizada, entre otras; que permitieron agilizar acuerdos e imponer condiciones para la construcción de la central. Comentamos a continuación algunas de estas prácticas identificadas por la población afectada.

\section{La desinformación}

Con relación al proceso de "información", previo a las "negociaciones", se encentraron quejas de la población, justamente respecto a la falta de información sobre derechos, impactos y compensaciones. Uno de los relocalizados por el proyecto afirmaba: "nunca estuvimos preparados para conocer nuestros derechos... no aceptaron que tuviéramos asesorías..."

El uso de términos como "expropiación” por parte de los funcionarios de la empresa habría hecho que una parte importante de los impactados se acogiera a la medida de compra directa. Muchos habitantes afirman haberse sentido intimidados por este lenguaje y desorientados por informaciones imprecisas sobre su futuro después de la construcción de la central. Uno de los entrevistados afirmo: "la falta de información, de asesoría, aumentó la cantidad de personas que aceptó compensación directa".

Igualmente, la empresa habría difundido la "información" de que si nuevos reclamantes de derechos llegaban a la zona, el dinero total de las indemnizaciones con que la empresa contaba tendría que ser dividido entre todos los reclamantes, estrategia que habría redundado en la confrontación entre pobladores con el objetivo de negar los derechos de algunos. Según otro de los pobladores, en principio la única medida de compensación ofrecida era la de compensación directa. Las opciones de reubicación y relocalización habrían sido ofrecidas después. Y continúa:

... cuando negociaron con nosotros, los primeros, solamente había compra directa. ¿Cómo podía yo decir cuánto costaba lo mío si yo no sabía para dónde ir?... no se hablaba de derechos de nadie, nosotros no valorábamos nuestras actividades... teníamos un más o menos, pero no teníamos certeza de esos ingresos... la psicología era: 'ahí está el avalúo catastral para hacerle el depósito en el banco. Solo le compramos lo que hay en el censo, porque lo que construyó después no se lo reconocemos'. Nosotros no conocíamos bien esa ley. Vinieron a hablar de relocalización después de un tiempo cuando comenzamos las protestas. (Entrevista)

Este reasentado aceptó compra directa inicialmente, y después de las protestas tuvo acceso a compensación con relocalización y proyecto agropecuario. 


\section{Buena imagen para la empresa y desincentivo a la articulación de la población con otros actores}

Otro poblador reubicado cuenta como en una comunicación enviada por la empresa se les invitaba a una reunión para la elección de un representante que participaría en la comisión tripartita para la elaboración del "manual de valores unitarios" para el cálculo de las indemnizaciones. Según su relato, la invitación fue hecha menos de una semana antes de la elección y el día de la elección no podía ser postergado.

Se destaca lo afirmado en el penúltimo párrafo de dicha comunicación: "Es importante que la comunidad tenga claro que para negociar con Empresas Públicas de Medellín no se requiere, en ningún caso, de intermediarios, ni de consecución de documentos o declaraciones extra juicio para acreditar su derecho como poseedores o propietarios de predios" (EPM, 2003, subrayado original, citado en Muñoz, 2015).

Se evidencia así, cómo la empresa pretendía usar su reputación de empresa socialmente responsable para evitar que las comunidades impactadas usaran mediadores que les ayudaran a reivindicar sus derechos.

\section{La cooptación de líderes}

En la reunión de elección del representante ante la comisión tripartita, los pobladores recibieron los requisitos que la persona debía cumplir, entre ellos, tener una profesión. Uno de los entrevistados recuerda que se postularon por lo menos dos personas: un profesor de uno de los centros educativos rurales y un abogado, resultando electo el primero. Sobre el papel que desempeño este representante en el proceso de negociación de los impactados y su relación con la empresa, algunos de los informantes sugieren lo siguiente:

(...) ja él le metieron la mano al bolsillo! El representante tenía mucha influencia en la región...

él hizo cosas buenas, como la gestión para electrificar la vereda. El fue buena gente, pero tiene sus cosas que se tragó solito (Entrevista)

En una circunstancia diferente, pero también de trato preferencial de uno de los líderes, uno de esto líderes cuenta como después de las protestas por reconocimiento de derechos, fue a ellos a quienes la empresa habría llamado primero:

La primera vez me ofrecieron 60 millones, después me subieron a 70, luego les dije que ochenta y después dije: resolví que no son 80, entonces a lo último me dijeron: "bueno, nosotros necesitamos esto, lo suyo son cien". Ya me habían cogido el número de cuenta de Amalfi, entonces metieron las máquinas, y bueno... entonces fuimos a atajar las máquinas porque me habían dicho de boca y no habíamos firmado nada y comenzaron a romper en lo mío. Entonces a las 6 de la tarde llegó un funcionario y dijo que dejara trabajar la máquina y que no había problema, que me respondían por la plata y les dije: ya se metieron, ya me han amenazado con leyes y carajadas, yo soy consciente de eso, como van a creer que el avalúo catastral es el avalúo de una propiedad, pero hagan lo que quieran con la tierra, pero con la casa no, yo no la entrego. (Entrevista) 
La situación que este poblador reconoce de haber sido tratado de forma diferenciada por ser un líder en la región es identificada también por otras personas de la comunidad. Tal es el caso de una de las entrevistadas que afirmo: "Ellos negociaron primero con los presidentes de las juntas". Algunos incluso dicen que los líderes se habrán dejado comprar por la empresa, traicionando a la comunidad.

\title{
La negociación individualizada
}

\begin{abstract}
Normalmente, para desarrollar dinámicas participativas se recurre a la representatividad de los actores sociales, pues no es práctico intentar llegar a todas las personas involucradas, con excepción de los asuntos que deben ser definidos de manera individual como el reasentamiento de población (Díaz, 2010, p. 77, resaltado nuestro).
\end{abstract}

Yo le dije [al funcionario de la empresa]: Yo creía que, al construir un proyecto con todos los derechos, yo no necesitaba negociar con bustedes, sino que bustedes sabían que me tenían que dar y que tenían que hacer conmigo, yo que le voy a ofrecer a usted si yo no estoy vendiendo mi finca y pa' donde me voy a ir con mis hijos, yo que hago (Habitante entrevistado)

Las anteriores citas evidencian como, tanto desde la concepción de los procesos de reasentamiento, como desde las prácticas efectivamente realizadas en el territorio, existe la idea de que lo natural es negociar individualmente con cada afectado. Los siguientes extractos de las entrevistas realizadas evidencian como las familias fueron conducidas una por una, a un espacio de "negociación" con muchas lagunas de información para la toma de decisiones, como visto antes.

Entonces nos citaban en una fecha específica, más o menos hasta 10 personas, estaba medio ambiente, sicólogos, abogados negociadores, pero no el representante de la vereda, que fue elegido, pero no intervino. En este punto habría sido deseable la intervención del representante de la comunidad o de una instancia de la defensoría del pueblo.

En este contexto de disparidad entre empresa y comunidades, la primera representada por un grupo de profesionales y las segundas por una sola persona o familia, en todos los casos sin más que una formación básica, los impactados se vieron avocados a negociar lo mejor que podían según sus capacidades de resistencia. En esa dinámica, los resultados de las indemnizaciones fueron variables, justamente en función de la capacidad de conseguir mejores condiciones de negociación por parte de cada familia o persona impactada.

Un caso que ejemplifica bien esta dinámica es el de uno de los impactados que negoció compra directa. En este caso la negoción fue variable desde el principio hasta el resultado final:

La empresa tiene gente engañadora para la comunidad, tramadora para negociar, con su perdón, porque tal vez usted estuvo en esa parte... primero me ofrecieron 15 millones de pesos, y yo me negué, después me llamaron y me trataron muy bien en la oficia, como si hubiera llegado el gerente de la empresa, me preguntó por la familia, y por todo, me ofreció cachuchas y camisetas, muy amables... y dijeron: 'le vamos a dar esto y si usted no lo reclama en tanto tiempo, le vamos a hacer un depósito en el banco y ya usted tendría que llevar abogado y el abogado se queda con la mitad de su plata, entonces es mejor que la reciba de una vez, son 22 millones 800 mil pesos, no más' (Entrevista) 
Un último testimonio resume bien el carácter de ese proceso de negociación: "ellos usaron psicología barata". El mismo poblador entrevistado cuenta que al momento de la negociación le dijeron que él solo llevaba tres años en la zona, según él, para disuadirlo en una estrategia que usaron para "pescar" a quienes llevaban poco tiempo de trabajar en el rio. En la primera negociación le ofrecieron 12 millones en compra directa, a lo cual él se negó. A los quince días volvió y esta vez le ofrecieron 36 millones. Ya con esa indemnización él "consiguió el derecho" a proyecto agropecuario.

\section{La criminalización de la protesta}

El uso de la fuerza pública al servicio de la criminalización de la protesta pacífica sería otra de las fuerzas por fuera de lo instituido, situación que además es común en el territorio colombiano para deslegitimar las reivindicaciones de la población movilizada. Esta práctica se evidenció en la detención ilegal, que según información de la comunidad habría hecho la fuerza pública por solicitud de la empresa, de los líderes de una de las manifestaciones realizadas en busca de mejoras en las negociaciones y de reconocimiento de derechos para familias, según el siguiente testimonio:

Para justificar la llevada de nosotros dijeron que estábamos violando las leyes, obstruyendo las vías... y nosotros estábamos era impidiendo el paso de maquinaria... Esa responsabilidad se la aplicamos a EPM, lo que estaba haciendo con nosotros... Que nos mandó la policía a que aplacara las cosas

\section{"Buscaban primero al hombre"}

Otra crítica que fue expresada por la población en relación al proceso de negociación se refería a la no inclusión de las mujeres en el inicio del mismo. Según uno de los entrevistados: "EPM vino a reconocer el patrimonio familiar, que en la familia tenían derechos los dos, ya tarde, buscaban al hombre para negociar y no a la mujer sabiendo que tenía tres o cuatro hijos al lado, eso causó problemas, de que fue el hombre que dispuso de la plata y por eso hoy hay hogares desbaratados". Según testimonio, el equipo de la "gestión social" habría intentado corregir esta falla durante el proceso de acompañamiento a la implementación de los proyectos productivos de las familias, a través de diversas actividades y modalidades. Sin embargo, como también confirmado, por él, hubo separaciones de parejas a causa de problemas en el manejo del dinero.

Estas prácticas parecen ser reiteradas y obedecer a una especie de manual no instituido pues se repite el patrón en otras regiones donde se desarrollan o pretenden desarrollar megaproyectos, tal como lo advierten los estudios de Insuasty, Alfonso (2016) y Olaya, Carlos (2015-2016)

\section{Conclusiones}

La "Gestión Social” para la construcción de la central hidroeléctrica Porce III es fundamentalmente un plan de acción estratégica, en la medida en que intenta dar solución a una necesidad de la empresa, cual sea el reasentamiento de la población impactada. Esta necesidad es, legalizada y legitimada de entrada por el Estado. Para tal objetivo, la empresa encontró una racionalidad técnica en la "planeación estratégica", contenida en la metodología de "Marco Lógico". Esta racionalidad le permitió emprender acciones a partir de la conversión de los impactos en objetivos, cada uno con un arreglo de programas, proyectos y actividades, todas ellas equivalentes a un costo monetario. 
Las técnicas fueron plasmadas u objetivadas en el "Plan de Gestión Social", en el "Manual de Valores Unitarios", en los "Contratos de reasentamiento", en el "Plan de Formación Integral"; y en el "Programa de monitoreo"; que adquirieron carácter legalmente instituido a través del proceso de licenciamiento ambiental, supervisado y aprobado por el Ministerio de Ambiente.

Sin embargo, la racional de la empresa mostró valerse de otras herramientas no instituidas, que tuvieron un carácter estratégico y no explícito en la consecución de los objetivos perseguidos en el corto plazo. Estas estrategias configuraron formas de acción en las que recursos, fuerzas o formas de poder de la empresa, tales como: (1) sus recursos monetarios; (2) la posesión y uso estratégico de la información, a veces precaria, a veces excesiva e a veces falsa; (3) el saber técnico sobre las transformaciones sociales y espaciales y una forma de manejarlas; y (4) su relación con la fuerza pública; le permitieron alcanzar objetivos como hacer viable la construcción de la central en el menor tiempo, al menor costo posible y evitando sanciones por retrasos.

Esta revisión de la racionalidad técnica de la "Gestión Social” presente en los planes, programas, proyectos y contratos, así como en las tácticas no institucionalizadas pueden ser asociadas a aquello que Boltanski afirma sobre la gestión empresarial como "la historia de la sofisticación permanente de los medios de dominación de todo lo que ocurre en la empresa y en el entorno” (Boltanski y Chiapello, 2002, p. 127); mostrando claramente las dos formas de acción empresarial descritas por estos autores en su obra titulada El Nuevo Espíritu del Capitalismo: la acción institucional y los desplazamientos o contornos a las restricciones de las instituciones para la obtención de beneficios. El proceso de sofisticación de las técnicas instituidas en la "gestión social" aquí descritas remite además a los análisis que Foucault (2006) hace sobre el poder pastoral en lo que él denomina "una extrema complicación de las técnicas y los procedimientos pastorales, una institucionalización muy rigurosa y densa..." (Foucault, 2006, p. 239).

Esta aproximación a la dimensión técnica del gobierno nos remite también al concepto de objetivación de las formas de capital usado por Bourdieu (2013, p. 51). Según este autor, existen formas objetivadas o mecanismos en los cuales las relaciones de poder son estabilizadas consiguiendo mostrar su efectividad. Para él, estos mecanismos son normalmente diseñados por los agentes detentores del tipo de capital en juego, notablemente jurídico, económico y estatal, que por medio de estos mecanismos imponen su necesidad sobre los agentes. En los casos del reasentamiento de población, las empresas tienen la capacidad de dominar esos mecanismos, lo que les permite la apropiación de los beneficios materiales y simbólicos producidos por su funcionamiento.

La posición estratégica conferida por estos mecanismos a la empresa ilustra también lo enunciado por Foucault (2008, p. 195) sobre el carácter eminentemente estratégico de los dispositivos. Así, se puede entender la dimensión técnica de los dispositivos como una forma de estabilización de las relaciones de poder que permite una ventaja estratégica a aquellos que los ingenian con base en saberes y conocimientos expertos y que son los conductores de su implementación.

En el tipo de instrumentos y técnicas analizados pueden observarse, al menos las condiciones de posibilidad, para la producción de efectos comparables a los identificados por Ferguson (1991) o por Miller y Rose (2012). El primero identifica efectos instrumento de los programas de desarrollo rural en África, que acaban introduciendo a las poblaciones en las dinámicas de la burocratización estatal y despolitizando los temas del desarrollo. Entre tanto, los segundos identifican la sujeción de los 
individuos a novedosos sistemas de control, o mejor, de autocontrol; como consecuencia de un gobierno a distancia ejercido en las sociedades contemporáneas, que ellos denominan como sociedades liberales avanzadas, aquellas sobrevinientes en Europa y Estados Unidos después del desmonte gradual del Estado de bienestar.

Si bien podría ser problemático hablar del liberalismo avanzado que plantean Miller y Rose (2012) aplicado a contextos latinoamericanos, los resultados aquí presentados sugieren que la promoción de la "autonomía" de los reasentados para la gestión de sus propios proyectos productivos estaba acompañada por la introducción de una lógica de la auto-medición contenida en los instrumentos y técnicas de monitoreo, lógica que los coloca en el terreno del desempeño individual, de la "cifra y de la rentabilidad" (Gaulejac, 2015, p. 76). A esta nueva forma de sujeción se unen aquellas generadas por una nueva relación con la tierra, el patrimonio, el crédito, el reporte y pago de impuestos al Estado, etc.; todas ellas relacionadas con el ejercicio de las nuevas actividades productivas después del reasentamiento. Los efectos de largo plazo de la exposición de las poblaciones a estas nuevas racionalidades y formas de sujeción quedan indicados como campo de posteriores investigaciones.

Finalmente y de manera parcial, concluimos que la racionalidad imperante en las técnicas de lo que viene siendo denominado "gestión social" de poblaciones impactadas por proyectos hidroeléctricos es parte de una racionalidad gestionaría, característica de las formas actuales de gobierno liberal, en las cuales los gobernados son convidados a participar activamente en el desarrollo de las actividades y prácticas de autogobierno, aquellas que fueron evidenciadas en el caso Porce III en la recurrente promoción de la "autogestión" y la "auto sostenibilidad", pero a condición de plegarse a nuevas formas de sujeción.

\section{Referencias bibliográficas}

Acselrad, H., Mello, C. Bezerra, G. (2006). Cidade, Ambiente e Política: problematizando a Agenda 21 local. Rio de Janeiro: Garamond.

Agamben, G. (2011). Qué es un dispositivo? Sociológica, 26 (73), 249-264. Disponible en http://www.revistasociologica.com.mx/pdf/7310.pdf (último acceso: 26 de marzo de 2016).

Arriagada, I. (2003). Capital social: potencialidades y limitaciones analíticas de un concepto Estudios Sociológicos, XXI, (3), 557-584. Disponible en file://C:/Users/gustavo.munoz/Downloads/Capital\%20social-

$\% 20$ potencialidades $\% 20 \mathrm{y} \% 20$ limitaciones $\% 20$ anal $\%$ C3 $\%$ ADticas $\% 20 \mathrm{de} \% 20$ un $\% 20$ concepto.pdf (último acceso: 28 de febrero de 2017)

Banco Interamericano de Desarrollo (BID). (2005). Proyecto Central Hidroeléctrica Porce III (COL1005). Disponible en http://idbdocs.iadb.org/wsdocs/getdocument.aspx?docnum $=565334$ (último acceso: 20 de abril de 2016).

Boltanski, L. y Chiapello, E. (2002). El nuevo espíritu del capitalismo. Madrid: Akal.

Bourdieu, P. (2007). Razones Prácticas, Sobre la teoría de la acción. Barcelona: Anagrama.

Bourdieu, P. (2013). Las estrategias de la reproducción social. Buenos Aires: Siglo Veintiuno.

Carvalho, I. (2001). Qual educação ambiental? Elementos para um debate sobre educação ambiental e extensão rural. Agroecologia e Desenvolvimento Rural Sustentável, Porto Alegre, 2 (2), 43-51. 
Disponible

http://www.mma.gov.br/estruturas/educamb/_arquivos/qual_educacao_ambiental_20.pdf (último acceso: 15 de julio de 2016).

Cernea, M. (1994) Making Development Sustainable: From Concepts to Action. World Bank Technical

Paper.

Disponible

en http://documents.worldbank.org/curated/en/514901468326404981/pdf/multi-page.pdf (último acceso: 20 de febrero de 2017)

Dean, M. (2010). Governmentality. Power and rule in Modern Society. Londres: Sage Publications Ltd.

Deleuze, G. (1991). What is a dispositif? in Michel Foucault: Philosopher. New York T.J. Armstrong (ed.): Harvester Wheatsheaf.

Díaz, M. (2010). Gestión Socioambiental en Megaproyectos, un enfoque integrador. Medellín: Fundación Codesarrollo.

Emgesa. (2016). Plan de Gestión Socioeconómico y Cultural. Obtenido de Emgesa: http://www.proyectoelquimboemgesa.com.co/site/Gesti\%C3\%B3nSocial/PlandeGesti\%C 3\%B3nSocioecon $\%$ C3\%B3micoyCultural.aspx

Empresas Públicas de Medellín E.S.P., EPM. (2002). Estudio de Impacto Ambiental del Proyecto Hidroeléctrico Porce III, 6.

Ferguson, J. (1994). The Anti-Politics Machine. "Development," Depoliticization, and Bureaucratic Power in Lesotho. London: University of Minnesota Press.

Foucault, M. (1980). Power/Knowledge, Selected interviews and other writings 1972-1977; Nueva York: Pantheon Books.

Foucault, M. (1991). The Foucault Effect: studies in governmentality. Burchell, Gordon y Miller (Eds.); Chicago: The University of Chicago Press.

Foucault, M. (2006). Seguridad, territorio, población. Buenos Aries: Fondo de Cultura Económica.

Foucault, M. (2008). Segurança, território, população. São Paulo: Martin Fontes.

Gaulejac, V. (2015). Gestão como doença social: ideologia, poder gerencialista e fragmentação social. [Traducción Ivo Stonriolo]. São Paulo: Ideias e Letras.

Gómez, L. (2010). Desarrollo Social con Energía. La Central Hidroeléctrica Guatapé, factor de desarrollo. Medellín: Fundación Codesarrollo.

Miller, P. y Rose, N. (2012). Governando o presente: gerenciamento da vida econômica, social e pessoal. [Traducción Paulo Ferreira Valerio]. São Paulo: Paulus.

Muñoz, E. (2013). Biopolítica empresarial na Amazônia Brasileira: estratégias de sustentabilidade e responsabilidade social empresarial da mineradora Alcoa em Juruti, estado do Pará. (Tesis Doctoral). Instituto de Pesquisa e Planejamento Urbano e Regional, Universidade Federal, Rio de Janeiro.

Muñoz, G. (2015). Formas de violencia en la construcción de la central hidroeléctrica Porce III en Antioquia - Colombia. Cuadernos de Trabajo Red WATERLAT-GOBACIT, 2 (2), 59-81.

Muñoz, G. (2016). De atingido a empreendedor: a política em tempos de "Gestão Social". O caso da Usina Hidrelétrica Porce III na Colômbia. (Tesis Doctoral) - Instituto de Investigación y 
Planeación Urbana y Regional, Universidad Federal, Río de Janeiro, (En proceso de publicación).

Pinto, R. (2013). O poder da crítica: um estudo sobre a relação empresa e movimentos sociais em um contexto de conflito ambiental. Estud. Sociol, 18 (35), 307-324. Disponible en https://www.researchgate.net/publication/281188476_O_poder_da_critica_um_estudo_so bre_a_relacao_empresa_e_movimentos_sociais_em_um_contexto_de_conflito_ambiental. (último acceso: 17 de mayo de 2016).

Vainer, C. y Araújo, F. (1990). Implantação de grandes hidrelétricas: estratégias do setor elétrico e estratégias das populações atingidas. Travessia, 1 (6), 18-24.

Vainer, C. y Araújo, F. (1992). Grandes projetos hidrelétricos e desenvolvimento regional. Rio de Janeiro: CEDI. 